\title{
¿Esto funciona? A propósito del concepto de "buena práctica" en materia penal
}

\author{
Pierre V. Tournier ${ }^{1}$
}

Director de investigaciones del Centro Nacional de Investigación Científica (CNRS)

Traducción de Alberto Manuel Poletti Adorno

\section{RESUMEN}

\begin{abstract}
Este ensayo analiza el concepto de "buena práctica" en materia penal y la forma en que la idea de eficacia puede ser interpretada en el discurso político en contraste con su uso en las ciencias sociales, en particular en relación con la evaluación de alternativas a la pena privativa de libertad.
\end{abstract}

\section{ABSTRACT}

This essay analyzes the concept of "good practice" in criminal justice and how the notion of effectiveness may be interpreted in political discourses in contrast with the way it is interpreted in the social sciences, particularly as relating to the evaluation of alternatives to incarceration.

\section{Introducción}

En marzo de 2003, el ministerio del Ministro de Justicia de Canadá nos proponía presentar una comunicación ${ }^{2}$ a la primera de las conferencias de una serie sobre las "Prácticas eficaces" que tenía como tema "Prácticas eficaces en materia de puesta en libertad bajo condición y de reinserción social" ("What works in Conditional Release and Community Reintegration"). En el documento de presentación, Wayne Easter, el ministro de justicia, hablaba también de "prácticas ejemplares" y de "ideas innovadoras". En mayo de 2004, a la iniciativa de la American Society of Criminology (ASC) (Sociedad Americana de Criminología) se realizará, en París, la primera conferencia de la sociedades de criminología sobre el tema: "What Works in Reducing Crime" ("Lo que funciona para reducir el crimen"). La Asociación francesa de Criminología (AFC) que presidimos será protagonista de esta manifestación de importancia. Para el título de la conferencia, fue retenida la siguiente traducción: "Reducir la delincuencia y la criminalidad: lo que funciona". Por último, el Consejo Científico Criminológico del Consejo de Europa, al cual pertenecemos desde junio de 2001, se ha propuesto elaborar una obra de presentación "de ejemplos prometedores". Estas son tres ocasiones para nosotros de enfrentarnos a esta forma, que se dice pragmática, de plantear las preguntas: respuesta evidente al "Nothing Works" ("Nada funciona") venido del otro lado del Atlántico. Tres ocasiones de reflexionar sobre las condiciones de un buen uso de la noción de "buena práctica"3.

Partimos de un ejemplo: la colocación de una persona bajo vigilancia electrónica (CVE), introducida en Francia a través de la ley del 19 de diciembre de 1997. La medida es innovadora, al menos para Francia, pero ¿esto funciona? ¿Es una práctica

\footnotetext{
${ }^{1}$ Director de investigaciones del Centro Nacional de la Investigación Científica (CNRS), Centro de Historia Social del Siglo XX, Universidad de Paris 1 Panthéon Sorbonne, Miembro del Consejo Científico Criminológico del Consejo de Europa.

${ }^{2}$ Tournier, P.V : La libertad condicional en Europa. Modelo discrecional contra Modelo de liberación de oficio, Conferencia "Prácticas eficaces en materia de puesta en libertad bajo condición y de reinserción social", Montreal, 2003, 9 páginas.

${ }^{3}$ Este artículo será objeto de una publicación en inglés en una obra preparada por el Consejo Científico Criminológico del Consejo de Europa.

Revista de Española de Investigación Criminólogica
} 
eficaz? ¿Una buena práctica? ¿Una práctica prometedora? Admitamos que estas diferentes formulaciones no son equivalentes. Pero si la última expresión está marcada por cierta prudencia, proyectándonos a un futuro, por naturaleza incierto, ¿no se trata, en definitiva, de simples figuras de estilo para designar la misma cosa? : ¿Una medida o una sanción penal (MSP) que conviene apoyar y desarrollar o incluso de vender en una $\mathrm{u}$ otra instancia internacional?

\section{La necesidad de definiciones}

Antes de contestar la cuestión de si ¿Esto funciona?, la primera exigencia metodológica ¿no es la de precisar de lo que se está hablando? Las sanciones penales son a menudo objetos polimorfos, un análisis pertinente de una de sus modalidades podría resultar errado en otra. La ley de 1997 ha consagrado la vigilancia electrónica como modalidad de ejecución de penas privativas de libertad. El artículo 723-7 del Código de Procedimientos Penales precisa que, en caso de condena a una o varias penas privativas de libertad que no excedan en su totalidad de un año, o cuando le queda por purgar al condenado una o varias penas privativas de libertad que no excedan en su totalidad de un año, el juez de aplicación de penas puede decidir que la pena se ejecutará bajo el régimen de colocación bajo vigilancia electrónica. La vigilancia electrónica puede igualmente decidirse como medida probatoria de libertad condicional para una duración que no exceda de un año. Así existen, en derecho francés, tres formas de vigilancia electrónica: la utilizada para una pena de menos de un año (modalidad I), la utilizada para el resto de una pena cuando ésta es inferior a un año de privación de libertad (modalidad II) y finalmente la colocación como medida probatoria de una libertad condicional (modalidad III). Agreguemos la existencia, desde la ley del 9 de setiembre de 2002, de una cuarta forma de vigilancia electrónica como condición particular de una medida de control judicial (modalidad IV). En este último caso muy diferente, la persona aún no ha sido juzgada. Ella no ha sido inscrita en un registro de encarcelamiento, contrariamente a las tres modalidades anteriores. Sin precisar por el momento el sentido de la pregunta ¿Funciona la vigilancia electrónica? Admitiremos fácilmente que la respuesta puede variar según la modalidad en cuestión, ya que si la medida técnica es la misma, ella puede ser aplicada en contextos bien diferentes: en el caso de una persona no encarcelada y no condenada (modalidad IV) como también en el caso de una persona detenida que viene de purgar quince años de reclusión criminal (modalidades II o III). La primera exigencia metodológica consiste entonces en rechazar toda respuesta global a una pregunta cuya forma invita, infelizmente, a este tipo de reacción.

\section{De la teoría sin la práctica}

Cuando el legislador introduce, en el aparato jurídico, una nueva sanción penal, ésta viene sin dudas con muchos atributos: es innovadora por naturaleza, eficaz (al menos eso se espera) y prometedora, la demostración quedando diferida para más tarde. La evaluación exige cierto retroceso; hay que dar tiempo al tiempo. Por eso, la cuestión de si ¿Esto funciona? tiene, durante la fase de lanzamiento, un sentido más trivial. Esta significa generalmente: ¿la sanción penal es efectivamente pronunciada? ¿Los actores de la justicia, que tienen este poder se atienen a casos significativos? En este nivel, la respuesta será antes que nada cuantitativa, en el sentido más banal del término. De ahí, en Francia, de octubre de 2000 (inicio de la experimentación) al primer de mayo de 2002 - dieciocho meses -, 175 colocaciones bajo vigilancia electrónica han sido 
ordenadas por los jueces de aplicación de penas ${ }^{4}$. Se contaron 150 medidas de vigilancia electrónica como "penas de menos de un año" (modalidad I), 22 vigilancias electrónicas como "resto de penas de menos de un año" (modalidad II) y 3 vigilancias electrónicas "medidas probatorias para la libertad condicional (modalidad III). Así podemos decir que la vigilancia electrónica "modalidad II" no funciona bien y que la vigilancia electrónica "modalidad III" no funciona en absoluto. Pero ¿a partir de qué base podemos decir que las cifras se convierten en importantes o prometedoras?

En la Estadística penal anual del Consejo de Europa "SPACE II" consagrada a las sanciones penales aplicadas en la comunidad ${ }^{5}$, pronunciadas un año determinado $^{6}$, hemos sido llevados a proponer dos indicadores para medir la importancia numérica de una u otra medida o sanción: un índice global de utilización (IGU), donde se relaciona el número de medidas o sanciones pronunciadas con el número de condenas privativas de libertad (sin suspensión a prueba de la ejecución, parcial o total), pronunciadas el mismo año, expresado sobre 100; y un índice específico de utilización (IEU), donde se relaciona el número de medidas o sanciones pronunciadas con el número de las condenas privativas de libertad de menos de un año ( $\sin$ suspensión a prueba de la ejecución, parcial o total), expresado sobre 100. Así, en 1999, en lo que se refiere al trabajo en beneficio de la comunidad, el índice específico de utilización era : 4,7 p. 100 en Moldava, 7,6 en Dinamarca, 28,7 en Suecia, 32,4 en República Checa, 34,5 en Francia, 36,1 en Finlandia, 58,0 en Escocia, 74,6 en Holanda, 88,4 en Inglaterra y País de Gales. Según la naturaleza de la medida o de la sanción y, en particular, de su carácter más o menos polimorfo, estos índices son más o menos pertinentes. Basta de pensar en las diferentes modalidades de la vigilancia electrónica a la francesa.

Pero independientemente de la cuestión técnica del cálculo de indicadores que no trataremos aquí ${ }^{7}$, se observa el carácter disimétrico de la interpretación de estas cifras: si son bajas, podemos señalar efectivamente que esto no funciona, y estas prácticas no pueden ser ni buenas ni eficaces ya que, sociológicamente, ellas no existen verdaderamente. Pero si las cifras son elevadas, concluir que esto funciona, es como tener una visión productivista, a corto término, con la que no se puede quedar satisfecho sin más elementos de información.

\section{Una medida puede esconder otra}

Cuando una persona que aún no ha sido sujeta a una detención provisional se beneficia de un control judicial socio-educativo y se ve posteriormente condenada a una pena con suspensión de la ejecución total, se puede pensar que esta medida individual de control le ha permitido escapar realmente a la prisión. Si ésta era la voluntad del legislador, al crear esta medida, se podría decir que isi funciona! Pero podemos afirmar también que el juez de instrucción no habría utilizado la detención provisional si el control judicial no hubiera existido en el ordenamiento jurídico. El juez ha utilizado una garantía suplementaria que le era propuesta. Si ello es así, este control judicial no

\footnotetext{
${ }^{4}$ Kensey, A, Pitoun A. Levy R, Tournier P.V, Bajo vigilancia electrónica. La puesta en marcha del

“ brazalete electrónico ” en Francia (Octubre de 2000, Mayo de 2002), Ministerio de la Justicia, Julio de 2002, 175 páginas.

${ }^{5}$ Recordemos que, en la terminología del Consejo de Europa, una MSP aplicada en la comunidad es una MSP no privativa de libertad - no en la prisión - acompañada de medidas de supervisión o sea de medidas de asistencia, ayuda y control.

6 Tournier, P.V., Estadística Penal anual del Consejo de Europa (SPACE II), Sanciones y medidas aplicadas en la comunidad pronunciadas en 1999, Consejo de Europa, Boletín de Información penológica No. 23 \& 24, 2002, 135-158.

${ }^{7}$ Índices de stock, de flujos, determinación de los denominadores más pertinentes...
}

Revista de Española de Investigación Criminólogica 
desempeña su papel de alternativa a la privación de libertad (¿alternativa virtual?) sino permite ampliar la red del control social. Es la teoría del net-widening, la ampliación de las redes de control. Esta misma cuestión puede de hecho más o menos realizarse sobre todas las alternativas a la detención que permiten evitar la entrada en prisión ${ }^{8}$. Tal condenado a un trabajo en beneficio de la comunidad ¿habría sido condenado a una pena de prisión cerrada si el trabajo en beneficio de la comunidad no hubiera existido en los textos? ¿No habría sido, llegado el caso, beneficiado de la suspensión a prueba de la ejecución de la condena simple o de una multa?

La pregunta se realiza en términos bastante diferentes para las alternativas que juegan no sobre las entradas sino sobre la duración de la detención (alternativas de segunda categoría). Un condenado al que le quedan tres años en reclusión criminal a ejecutar, al que se le otorga una libertad condicional beneficia de una real alternativa. Él efectuará el resto de su pena de tres años fuera de prisión. Y sin embargo...

Lo sabemos, las libertades condicionales se han vuelto cada vez más raras. El Parlamento francés y el gobierno han tomado conciencia y han terminado por comprometerse en una reforma importante de los procedimientos de concesión en el marco de la ley del 15 de junio de 2000. Imaginemos que la reactivación esperada de la libertad condicional sea efectiva. ¿Ello no producirá una aumentación compensatoria del quantum de las penas pronunciadas por las jurisdicciones, frustradas de ver "sus" sanciones demasiado erosionadas? De ahí que una segunda categoría, bien real, al "nivel micro" - el beneficiario no tiene ninguna duda - puede volver bien virtualmente al nivel "macro".

Para las medidas de tercera categoría que reducen el tiempo pasado tras las rejas, pero sin suspender la inscripción en el registro de encarcelamiento, es necesario distinguir las medidas ab initio - tomadas desde el inicio de la detención - de las demás. Tomemos el caso de la vigilancia electrónica correspondiente a la ejecución de una pena de menos de un año (modalidad I). ¿Las jurisdicciones no estarían tentadas a pronunciar penas de prisión cerrada de menos de un año en los casos donde antes ellas habrían acordado la suspensión a prueba, sabiendo que el condenado podría escapar a la detención gracias al brazalete electrónico? Razonamientos de los más aleatorios ya que podemos imaginar el catastrófico escenario que sigue: el Tribunal Correccional pronuncia una pena de prisión cerrada de seis meses por ejemplo, antes que una suspensión a prueba de la ejecución de la condena con condiciones, pensando que ésta será ejecutada en el marco de una colocación bajo vigilancia electrónica, pero que el juez de aplicación de la pena, sobre quien recae la decisión de colocación, la rechaza. Lejos de ser entonces una alternativa a la privación de libertad, la vigilancia electrónica favorece el recurso a la prisión.

En cambio, la vigilancia electrónica al fin de la pena no presenta el mismo tipo de interrogación (modalidad II). Por otro lado, el caso de las medidas probatorias a la libertad condicional es particular: semi-libertad, colocación al exterior, vigilancia electrónica según la modalidad III. Su existencia puede favorecer la concesión de la libertad condicional aumentando las garantías sobre las cuales puede apoyarse el juez de aplicación de la pena. Pero ello puede retardar la puesta en libertad condicional. Sin estas medidas, la libertad condicional habría podido ser efectiva a contar de la fecha $\mathrm{T}$;

\footnotetext{
${ }^{8}$ Es lo que llamamos una alternativa de 1ra categoría por oposición a las medidas y sanciones que permiten solamente reducir la duración de la detención, alternativas llamadas de 2 da categoría como la libertad condicional por ejemplo. Por último, se conoce como alternativas de 3ra categoría, las alternativas que permiten reducir el tiempo pasado tras las rejas, sin reducir el tiempo pasado en detención (la semi-libertad) por ejemplo. Ver Tournier P.V., ¿Hacia prisiones sin detenidos? A propósito de la introducción de la colocación bajo vigilancia electrónica en Francia, Consejo de Europa, Boletín de Información penológica, No. 23 \& 24, 2002, 3-6
}

Revista de Española de Investigación Criminólogica 
con sus medidas, el detenido sale solamente en la fecha $T+T^{\prime}$; alternativa virtual ya que, ésta tiene, en realidad, el efecto de aumentar el tiempo de detención. ¿Las medidas y sanciones penales tendrían un parentesco con Janus?

\section{Pronunciar no es llevar a ejecución}

Supongamos que una sanción penal innovadora sea efectivamente pronunciada, cada año, en un número significativo de casos, y además oportunamente. Los analistas menos difíciles concluirán, lo hemos visto, que esto funciona; otros estarían con derecho a preguntarse sobre la puesta en ejecución de estas sanciones penales. Tema delicado en sí, ya que lo que se entiende por puesta a ejecución corresponde a exigencias muy diferentes según la naturaleza de la sanción penal, pero también a expectativas de parte del analista más o menos imperativas para la persona procesada.

La puesta en ejecución de una pena puede limitarse a un simple registro: es el caso de la suspensión a prueba de la ejecución de la condena simple (suspensión de la ejecución de una pena privativa de libertad sin seguimiento de condiciones) que basta con la inscripción en la Planilla de Antecedentes Penales. La puesta en ejecución de una pena de privación de libertad cerrada es más compleja cuando el procesado ha salido en libertad luego del juicio: se necesita a veces la actuación de los servicios de policía para la búsqueda de la persona, hay problemas de plazos de prescripción, etc. Sin embargo, no hay problema de definición en lo que se refiere a la ejecución: la persona será detenida o no.

Las cosas se complican para las sanciones penales aplicadas en la comunidad. Tomemos el caso de la pena de trabajo en beneficio de la comunidad, introducida en Francia en 1983, con dos variantes: como pena principal o como condición de una suspensión a prueba de la ejecución de la condena con condiciones. En el proceso de ejecución del trabajo en beneficio de la comunidad, pueden distinguirse cuatro etapas concretas: a. La audiencia del condenado con el juez de aplicación de la pena donde el primero será notificado de la sanción, b. La audiencia con el consejero de inserción y probation (CIP) - asesor de prueba - con quien examinará las condiciones prácticas de la ejecución, c. El primer contacto del condenado con su empleador, d. El inicio efectivo del trabajo (la puesta en funciones). Esta sucesión de encuentros, en marcos definidos por la ley, con ciertos condenados, muy desestabilizados o que tienen problemas de adicción o sufren de problemas mentales, o no tienen domicilio fijo, puede servir como el recorrido de un combatiente. ¿Debemos considerar que hay ejecución desde que la notificación del juez de aplicación de la pena ha sido efectuada o, con una visión menos estrechamente jurídica, esperar la puesta en funciones? Vemos en este ejemplo la evaluación de una ejecución que funciona no se da sin colocar los presupuestos de definición.

\section{A vencer sin peligro}

Que una sanción penal pueda ser ejecutada en las condiciones materiales o de tiempo satisfactorias es una cosa. Pero ¿hablaríamos de buena práctica si, después, las circunstancias no ocurren de buena manera? ¿Cuáles serían los incidentes que podríamos considerar como benignos y que no inciden sobre la buena ejecución de la sanción penal? ¿Con qué indulgencia o con que severidad las infracciones de la persona procesada serían evaluadas? Aquí, como en otras cuestiones, la política del zero default, para no citar la de la tolerancia cero puede corresponder a una política de corto alcance. Para mostrar que una práctica innovadora es una buena práctica, los responsables de su 
aplicación ¿no se exponen a ser embelesados por los asuntos de la incidencia, del fracaso, al punto de desviar la medida de su verdadero objetivo? Retornamos a la situación anterior: para que ello funcione, es decir para que no se presenten incidentes durante la ejecución, se correría el riesgo de pronunciar la medida con relación a condenados fáciles de manejar para los cuales la medida no ha sido realmente creada. En cuanto a los demás, "los clientes difíciles", ellos continuarán siendo objeto de buenos viejos métodos que sin duda alguna no funcionan. Y los partidarios, poco exigentes, de la nueva medida estarán satisfechos: la medida es 1) pronunciada, 2) puesta en marcha, 3) ejecutada sin incidentes. ¿Qué más se puede pedir? Es perfecto. Otros sienten las ganas de realizarse preguntas complementarias sobre el futuro del condenado en términos de condiciones de vida, de reinserción, de reincidencia.

\section{Después de la pena}

Entre las múltiples funciones de las medidas y sanciones penales se encuentra, evidentemente, la idea, para la sociedad, de protegerse de una eventual reincidencia, en el sentido amplio del término. En este nivel, ¿la buena práctica no es la que asegurará la reincidencia cero, al menos, seamos realistas, la frecuencia de la reincidencia más baja, la tasa de reincidencia más pequeña? Nos apartamos entonces de las visiones anteriores, de horizontes limitados, para proyectarnos en el futuro de los individuos. Pero allí aún, existen diversas maneras de abordar este proceso: ¿sobre qué período se quiere tener en cuenta el comportamiento de los antiguos procesados? ¿Cuál será el criterio a retener para la "reincidencia" y en su caso, para hablar de fracaso? ¿Una nueva condena? ¿Una condena de cierta gravedad? ¿Hechos de determinada naturaleza? Para evaluar la calidad de la sanción penal, se tendrá en cuenta un criterio de reincidencia por encima del cual se podría decir que esto no funciona $(1 \%$ ?, 10\%?, 20\%?, 50\%?) ¿O se podría entrar sobre el dificultoso terreno de comparación entre medidas?

Si nos apoyamos sobre nuestra experiencia en el debate público del tema, en Francia, nos encontramos con un bajo nivel de rigor sobre los propósitos tenidos por unos y otros mientras que el campo se halla señalizado por muchos trabajos en la materia 9 . Por ejemplo, métodos originales han sido desarrollados para comparar las tasas de retorno a la prisión ${ }^{10}$ observadas en ciertos condenados a una pena privativa de libertad cerrada según que ellos hayan sido beneficiados o no de una libertad condicional. La comparación, lo sabemos, milita en favor de la libertad condicional respecto a lo que se llama a veces "las libertades secas" (no preparadas, al final de la pena $)^{11}$. Esta técnica llamada de las "tasas comparativas", tomada del análisis demográfico, permite distinguir, en la diferencia de niveles, lo que puede ser atribuido al procedimiento de selección de los beneficiarios de la libertad condicional y lo que puede ser atribuido a la medida en sí misma: salida preparada, asistida, controlada ${ }^{12}$. De manera general, no podemos contentarnos de comparar directamente la tasa de reincidencia relativa a la sanción penal A y la tasa de reincidencia relativa a la sanción penal B, sin tener en cuenta las diferencias de estructuras entre las dos poblaciones A y $\mathrm{B}$, según las variables que pueden influir directamente o no sobre la frecuencia de la reincidencia. Dicho de otra manera, detrás de un buen nivel de reincidencia ¿podría

\footnotetext{
${ }^{9}$ Tournier P.V. A cada uno su verdad. Declaraciones sobre la reincidencia, ante la Asamblea Nacional y el Senado, Cahiers de l'Actif, No. 296-297, 51-64.

${ }^{10}$ Existencia de una nueva pena privativa de libertad.

${ }^{11}$ Warsmann, J-L, Las penas alternativas a la detención, las modalidades de ejecución de las cortas penas, la preparación de los detenidos a la salida, Informe ante el Ministerio de Justicia, 2003.

12 Tournier P.V. La medida de la reincidencia en Francia, La Documentation Française, Miradas en la actualidad, 229, 15-23.
}

Revista de Española de Investigación Criminólogica 
esconderse una buena estructura socio-demográfica y o penal, mientras que uno esperaría reconocer los efectos de una buena práctica?

Queda la pregunta sobre la interpretación de estos famosos niveles de reincidencia, incluso cuando son calculados correctamente, o incluso cuando se los tiene en cuenta, lo más posible, las cuestiones metodológicas que surgen de las comparaciones entre las sanciones penales. En efecto, las investigaciones sobre la reincidencia solo toman en cuenta los nuevos hechos conocidos por el sistema penal. Así, nuestro colega Pierre Landreville prefiere hablar de "tasas de recaída"13. Estas tasas no permiten dar una imagen fiel de la población que ha cometido de nuevo hechos susceptibles de ser calificados penalmente y por eso, pueden modificar la evaluación de la medida.

\section{Costos y ventajas}

¿Esto funciona? ¿Vale la pena/el costo ${ }^{14}$ Otra expresión del lenguaje corriente, otro ámbito de preocupación en términos de evaluación. La gran ventaja de los cálculos económicos es, al menos, la de saber en que unidades de cuenta uno va razonar: en euros. Lo que da la apariencia de facilidad: introduciendo la distinción entre costos de inversión y costos de funcionamiento, teniendo en cuenta el número de personas a quienes concierne la sanción penal, tornando progresivamente complejo el modelo para tener en cuenta las duraciones de puesta en marcha, se debería llegar a algo. Pero se podría descuidar, por el camino, todo lo que no entra en una lógica puramente contable, el precio de la libertad, por ejemplo, como el precio de los daños colaterales ${ }^{15}$ de la prisión sobre la familia y las personas cercanas al detenido. Queda de todas formas la cuestión de poner en relación estos costos y las ventajas. Y se vuelve a los puntos precedentes.

Algunas de estas observaciones son para muchas de ellas simple sentido común. Cada una merecería sin duda desarrollos más profundos y más técnicos. Ellas no ponen en duda la necesidad, en democracia, de la evaluación de las políticas penales y penitenciarias como de toda otra política pública, por el contrario. Se trata, para nosotros, de una invitación a renunciar, no a la pregunta de si esto funciona sino a las respuestas reducidas de los partidarios como de los sostenedores y denigradores de una u otra innovación. No existe una solución mágica y ninguna solución, que respete los derechos de la persona, debe ser rechazada inmediatamente.

\footnotetext{
${ }^{13}$ Landreville P, La reincidencia en la evaluación de las medidas penales, Déviance \& Société, Vol. 6, No. 4, 366-375.

${ }^{14}$ Hace algunos años, una asociación francesa de ayuda a las familias de los detenidos, la FARAPEJ, ha utilizado este título para un coloquio ("Est-ce que ça vaut le coup/coût?").

${ }^{15}$ La expresión, muy clara, fue propuesta por una persona privada de su libertad.

Revista de Española de Investigación Criminólogica
} 